\title{
LENGUAJE POÉTICO Y METÁFORA EN LA OBRA DE ERNESTO GRASSI ${ }^{1}$
}

\author{
Joaquín Barceló \\ Universidad Andrés Bello \\ jbarcelo@unab.cl
}

\begin{abstract}
Resumen
Heidegger reivindicó la primacía del lenguaje poético sobre el lenguaje racional de la metafísica tradicional, pero rechazó el uso de la metáfora en él. Su discípulo Grassi atribuye en cambio a la metáfora una fundamental importancia filosófica, no solo por su función en el arte, la técnica y la vida humana en general, sino también porque todo cuanto se manifiesta a través de los sentidos (donde se inicia el conocimiento) se carga inevitablemente de significados pasionales ajenos en sí mismos a las representaciones sensoriales, de modo que todo lenguaje que expresa una realidad es en su esencia metafórico.
\end{abstract}

Palabras Clave: humanismo, lenguaje poético, metáfora, pasiones, sensibilidad, significado.

\section{Abstract}

Heidegger defended the primacy of poetic language over the rational language of traditional metaphysics, though rejecting the use of metaphor in such language. His disciple Grassi, however, attached the greatest philosophical importance to metaphor, not only for the role it plays in art, technology, and human life in general, but also because everything that becomes manifest through the senses -where knowledge begins-inevitably becomes charged with passionate meanings in themselves alien to sensory representations; thus any language that expresses a reality is in essence metaphorical.

KEYWORDS: Humanism, poetic language, metaphor, passions, sensibility, meaning.

17 "Yo estimaba mucho la elocuencia y estaba enamorado de la poesía; pero pensaba que la una y la otra, más que frutos del estudio, eran dones del espíritu. Quienes poseen un razonamiento más sólido y dirigen mejor sus pensamientos con

Este trabajo forma parte de los resultados del proyecto de investigación DI-34-05/R de la Universidad Andrés Bello. 
el fin de hacerlos claros e inteligibles, siempre pueden persuadir mejor acerca de lo que proponen, aunque no hablen más que bajo bretón y jamás hayan aprendido la retórica. Y los que hacen los hallazgos más gratos y pueden expresarlos con más ornato y dulzura, no dejarán de ser los mejores poetas, aun si el arte poética les es desconocida". Estas frases figuran en la primera parte del Discours de la méthode publicado en 1644 por el "padre de la filosofía moderna". Cierto es que con ellas Descartes no estaba proponiendo ninguna novedad, al menos en lo concerniente a la poesía en cuanto lenguaje comunicativo, porque ya en el siglo XIII había afirmado Santo Tomás de Aquino que "lo poético no es comprendido por la razón humana debido a la falta de verdad que posee" (ST, $\mathrm{I}^{\mathrm{a}} \mathrm{II}^{\mathrm{ae}}$, q. 101, a. 2 ad 2). De aquí se derivó la tradicional desvalorización de la poesía como expresión del conocimiento y del saber, desvalorización que culminó en el idealismo alemán y la filosofía hegeliana. Con todo, a mediados del siglo XX, Martin Heidegger escribió, entre otras cosas: "El fundamento del Dasein humano es el coloquio como acontecer propio del lenguaje. Pero el lenguaje originario es la poesía como fundación del ser" (Heidegger 1951, p. 40). A pesar de Santo Tomás, de Descartes y de Hegel, el lenguaje poético cobra en manos de Heidegger una primacía antes insospechada: es nada menos que fundación del ser, Stiftung des Seins. Sin embargo, en esta concepción del lenguaje poético Heidegger no consideró la metáfora, como lo haría más tarde Grassi, porque la tuvo más bien por un expediente de la metafísica onto-teo-lógica, que supone un dualismo entre un mundo sensible y otro no sensible que le sirve de fundamento, de manera tal que el filósofo vio la metáfora como una figura obsoleta y rechazable ${ }^{2}$.

Discípulo de Heidegger fue Ernesto Grassi (1902-1991). Como discípulo, éste adoptó las tesis básicas y la línea fundamental del pensamiento del maestro, pero discrepó de él en dos aspectos. El primero, en la adhesión de Heidegger al nacional-

2 M. Heidegger (1958, pp. 88-9): "La representación de lo 'figurado' [literalmente 'traslaticio', übertragen] y de la metáfora reposa sobre la distinción, si acaso no sobre la separación de lo sensible y lo no sensible como dos ámbitos autosubsistentes, El establecimiento de este divorcio entre lo sensible y lo no sensible, entre lo físico y lo no físico, es un rasgo fundamental de lo que se llama metafísica y determina normativamente al pensamiento occidental. La comprensión de que dicha distinción de lo sensible y lo no sensible es insuficiente, hace que la metafísica pierda el privilegio de la normatividad del pensamiento". Cfr. También Heidegger 1984, p. 17 ss. No deja de ser curioso que el creador de metáforas o expresiones metafóricas tan llenas de significado como "el claro del ser" (die Lichtung des Seins) o el hombre como "pastor del ser" (der Hirt des Seins) o el lenguaje como "la casa del ser y la morada de la esencia del hombre" (das Haus des Seins und die Behausung des Menschenwesens), rechace la metáfora como un expediente obsoleto; el hecho, sin embargo, requiere probablemente de una interpretación, porque el de Heidegger no es el único caso; también Hobbes, quien, en la introducción a su Leviathan, explicó la naturaleza del Estado político con la magnífica metáfora de un animal artificial, escribió en la misma obra que "las metáforas y las palabras ambiguas o carentes de sentido son como ignes fatui, y razonar sobre ellas es ir de un lado a otro entre innumerables absurdos" (Hobbes, I, 5, p. 30).). 
socialismo y su consiguiente actitud adversa hacia sus colegas y estudiantes de origen judío; el segundo, en la valoración negativa de la tradición latina y del humanismo por parte de Heidegger, para quien este último movimiento representaba una simple antropología que formaba parte del "olvido del ser" imperante en la tradición filosófica occidental. Grassi pudo identificar, en cambio, un humanismo caracterizado por hacer partir la reflexión filosófica no desde el problema de los entes, con ignorancia de la diferencia ontológica heideggeriana, sino desde el problema del lenguaje; este humanismo, que podría llamarse retórico, se inicia para Grassi en la antigua Roma con Cicerón, se trasmite por cauces más o menos subterráneos durante la Edad Media, rebrota en los humanistas no platonizantes de la época renacentista italiana, encuentra seguidores aislados en pensadores como Erasmo de Rotterdam, Juan Luis Vives y Baltasar Gracián, y culmina en la obra del napolitano Giambattista Vico. Del humanismo así concebido sostiene Grassi que en él hay que buscar el origen de la filosofía moderna, donde obviamente él no entiende por "filosofía moderna" el racionalismo del siglo XVII, ni el materialismo ilustrado del XVIII, ni el idealismo o el positivismo del XIX, sino concretamente la que comienza con Heidegger en el siglo XX.

En su "arreglo de cuentas" con Heidegger, Grassi se preocupó especialmente de reivindicar la importancia filosófica de la metáfora, desvalorizada por su maestro. Para Grassi, la metáfora no es tan solo un vehículo idóneo para comunicar cierto tipo de conocimientos (cosa que ya habían enfatizado los antiguos maestros de retórica, como Cicerón o Quintiliano), sino también el fundamento de la posibilidad misma del lenguaje. Hoy es frecuente reconocer que todo lenguaje tiene carácter metafórico, pero no es habitual señalar el porqué del cuantificador universal todo en este enunciado. Dicho "porqué" implica también una modificación del concepto mismo de metáfora; porque si ésta se entiende como la transferencia de un significado de un término a otro o de un objeto a otro, se está presuponiendo que las cosas o los términos tienen un significado "propio" y que la metáfora consistiría en asignarles un significado "impropio" o "figurado", de manera que el lenguaje sería solo parcialmente metafórico; en él coexistirían, en efecto, metáforas con términos que conservan su significado propio. De este modo, si la metáfora es el carácter propio de todo lenguaje, o su fundamento, como sostendrá Grassi, ella no puede consistir en el simple traslado de un significado de un término a otro. Aquí intentaremos precisar en qué consiste para Grassi la metáfora, y dar cuenta de las razones que él tuvo para universalizar la afirmación del carácter metafórico del lenguaje.

Grassi parte de un hecho comúnmente aceptado: nuestro conocimiento se inicia con la actividad de los sentidos, con la representación de imágenes de origen sensorial. Desde antiguo se ha reconocido, empero, que los datos sensoriales, considerados en sí mismos y desvinculados de la actividad de otras facultades cognoscitivas humanas, no constituyen sino una lluvia de sensaciones que nos pone frente a un caos carente de todo orden y significado. A ello se añade el agravante de que las representaciones sensibles no solo se suceden ininterrumpidamente las unas a las otras, sino 
que además, si algunas de ellas podrían ser reconocidas como vinculadas a un mismo objeto, manifiestan cambios incesantes en sus contenidos mismos, de manera tal que la identidad del objeto se hace fluida y, en último término, irreconocible. En suma, la sola actividad sensorial nos pone frente a un caos en el que es imposible orientarse. Es, por consiguiente, de la mayor importancia, y no solo para la vida intelectual, sino también para la vida biológica, poder introducir en dicho caos un orden que nos permita identificar significados para las diferentes representaciones y ajustar nuestra conducta a dichos significados.

¿Por qué, empero, es preciso ordenar e identificar significados en lo que nos entrega la actividad sensorial? Estamos aquí frente a un imperativo de la vida. En los niveles de la vida animal caracterizados por la motricidad existen al menos dos solicitaciones básicas que con su apremio plantean al ser vivo desafíos urgentes: la búsqueda de alimento y la huida del depredador específico. En los niveles en que aparece la sexualidad, la posibilidad de reproducción se muestra como una nueva solicitación apremiante. Las caóticas experiencias sensibles mediante las que el ser vivo toma el primer contacto con su mundo circundante deben ser decodificadas por él para que adquieran un significado en relación con estas necesidades mínimas: posibilidad o imposibilidad de nutrición, presencia o ausencia de peligro vital, posibilidad o imposibilidad de reproducción. A diferencia de los códigos convencionales arbitrariamente establecidos por los seres humanos con diversas finalidades, los códigos utilizados por los seres vivos para descifrar el significado de las impresiones sensoriales le son impuestos a cada especie por la vida misma y los llevan a actuar de la manera que tradicionalmente se ha llamado "instintiva". Si imaginamos que algún accidente biológico alterara el código de una especie animal y debido a ello no le permitiera "reconocer" el alimento, el depredador específico o el sexo en combinación con el cual su reproducción se hace posible, es claro que la especie así afectada no podría sobrevivir. Este modelo elemental puede expandirse para cubrir también otras solicitaciones con que el mundo circundante apremia a las especies vivientes, y dicha expansión puede llegar a sobrepasar igualmente los contornos de la vida meramente biológica para incluir las solicitaciones y apremios procedentes del mundo de la cultura, y aun de la vida que llamamos propiamente espiritual, propios de la especie humana. Entre los antiguos griegos se reconocía la existencia de una entidad divina, la Confusión (Ate); cuando ella se apoderaba de un mortal, a éste lo bueno le parecía malo y lo malo, bueno; tal hombre estaba ya irremisiblemente perdido.

La consideración precedente apunta, en toda su elementalidad, a la necesidad de hallar principios que nos permitan ordenar el caos sensorial y orientarnos en él, de modo que podamos atribuir significados unívocos a las diversas manifestaciones sensibles, abriendo así la posibilidad de no sucumbir en el trato con una realidad cuyo carácter se ignora. Es claro que tal búsqueda de principios orientadores no es indispensable tan solo en el nivel de la actividad sensorial, sino que se revela también como absolutamente necesaria en todos los niveles del proceso cognoscitivo. La 
historia del pensamiento filosófico occidental nos entrega noticias de diversos enunciados que, en los distintos niveles cognoscitivos, han sido establecidos como principios ordenadores de la realidad y orientadores de nuestra conducta en el trato con los entes: principios lógicos, metafísicos, morales, jurídicos, científicos, prácticos, etc. Las diversas posibilidades que se abren para esta suerte de hallazgos de principios han planteado empero el problema de la objetividad. ¿Cuáles son, en efecto, aquellas representaciones o enunciados que podemos legítimamente reconocer y aceptar como principios ordenadores y orientadores, sin que nos defrauden en la confianza que hayamos podido depositar en ellos? La objetividad se opone a la elección arbitraria y caprichosa de enunciados o representaciones a los que se atribuiría antojadizamente el carácter de principios ordenadores y orientadores, pero que, a fin de cuentas, defraudarían en el empeño de ordenar y de atribuir significados válidos a los caóticos datos sensoriales y a los múltiples enunciados intelectuales.

El problema de la objetividad es de primera importancia en la actividad científico-natural, pero en ésta puede ser resuelto, en parte al menos, con ayuda de la experimentación. Mayor dificultad ofrece en disciplinas como la historia o la filosofía, donde la experimentación es imposible. Cuando nos colocamos en el nivel de los fundamentos de la lógica o de la metafísica, la dificultad parece conducir a una aporía. ¿Cómo distinguir un auténtico principio ordenador de los seudoprincipios falaces y no perdurables? Evidentemente, la validez de un principio primero del pensamiento no puede ser "demostrada" por éste, ya que son ellos, los principios mismos, el fundamento y punto de partida originario de toda demostración. Pero Aristóteles planteó magistralmente el problema de los principios primeros, al discutir el principio de no contradicción, y propuso que, como éste no puede ser demostrado apodícticamente, puede al menos ser probado por refutación (elegktikôs) de quien lo niegue (Aristóteles $M$, IV, 4; Grassi 1933 pp. 23-6). En efecto, negar el principio de no contradicción supone admitir a la vez la falsedad de la propia negación y de cualesquiera otras aserciones, de manera semejante al modo en que Descartes no podía revocar en duda su principio del cogito sin presuponerlo. Por este motivo, Grassi ve que los principios originarios se imponen sobre los seres humanos. "Lo objetivo", dice en una de sus obras tempranas, "no es [...] lo que hay, lo que está ahí, sino algo que por su propia fuerza se le impone al hombre. Aquello que hay, que siempre se muestra diferente en su relación con éste o aquél, se revela como altamente subjetivo en cada individuo. Lo objetivo, en cambio, se funda en sí mismo e independientemente en cada ser individual. Por consiguiente, lo común no se alcanza en la confusión de todos los sentimientos. Precisamente aquello que no entendemos en la primera lectura de un poeta nos parece al comienzo inaccesible, pero no porque sea algo subjetivo sino porque lo poético es tan objetivo que no podemos alcanzarlo, no logramos verlo con nuestros criterios subjetivos cotidianos" (Grassi 1946, p. 33; cfr. Grassi 1951). Por eso, los seres humanos inevitablemente hemos de someternos a los principios y "padecerlos". Más adelante, podremos comprobar que en Grassi este "padecer los principios" ni siquiera es una metáfora; el padecer, lo patético, es para él un carácter esencial del saber y del lenguaje humanos. 
Lo originario, empero, no ha de buscarse solo en la lógica o en la metafísica, sino dondequiera tengamos que padecer principios que se nos imponen como tales sin dejarnos escapatoria; tales principios aparecerán en la vida política, en la actividad científica, en la creación artística y, por cierto, en la poesía. En virtud de esta experiencia de lo originario en el ámbito de la poesía concibieron los antiguos griegos el mito de la musa, la fuerza divina que se apodera del poeta, le priva del dominio sobre sí mismo y le comunica la visión que del mundo y de los acontecimientos humanos tiene la divinidad, dotando de este modo a la poesía del más alto nivel de objetividad. Ésta, y no otra, es según Grassi la tesis de Platón en su diálogo Ion (Grassi 1946, pp. 4558). Como es sabido, con frecuencia se ha interpretado este diálogo platónico como un ataque a los poetas y rapsodas, quienes, arrebatados por el entusiasmo y habiendo perdido el control de su propia razón, se hacen merecedores de ser expulsados de la ciudad, como lo prescribe el mismo Platón en su República. Grassi, empero, considera el Ion como el reconocimiento por parte del filósofo de que el poeta está poseído por lo divino, es decir, ha logrado el contacto con una fuerza originaria trascendente que lo domina y ha quedado sometido a su poder. En el fondo, el problema de la poesía es el del fundamento del arte y de toda actividad creativa: "Cuando Platón vincula el origen de la poesía o de toda creación artística con la experiencia de una armonía divina, o visualiza el origen de toda actividad artística productiva en una tensión originaria [entre lo eterno extratemporal y lo temporal], allí se halla el fundamento de la poiesis que conduce del no-ser al ser, cualquiera pueda ser la ulterior determinación de la esencia del arte" (Grassi 1957, pp. 71-2).

¿Qué ocurre entretanto con el lenguaje poético y la metáfora?

Ya en 1970 (Grassi 1970, p. 169 ss.), observaba Grassi cómo el pensamiento lógico, para expresar sus conceptos, debe recurrir a metáforas que remiten principalmente a lo visual, como es, por ejemplo, el caso cuando se habla de "explicar" (< explicare, desplegar, desenredar), de "comprender" (< comprehendere, abarcar, coger), de concluir (< concludere, cerrar, encerrar), etc. ${ }^{3}$ La palabra misma "metáfora" es de suyo una metáfora, porque el verbo griego metapherein significa trasladar algún objeto de un lugar a otro. De manera sistemática, los antiguos concibieron la metáfora como el traslado de un significado de un término a otro, y concretamente, desde un término que designa una realidad sensible hacia uno cuyo referente es ajeno al mundo sensorial; así, por ejemplo, un "discurso brillante", una "reflexión amarga". En el caso de la poesía, y según la interpretación tradicional, lo trasladado sería el significado de una palabra a otro término. ¿Se trata empero de un simple traslado, o bien del descubrimiento previo de una relación que vincula al lugar "desde donde"

3 Consideremos también que en los fundamentos mismos de la lógica de clases se parte de tres conceptos no definibles: el de "clase", el de "elemento" y el de "pertenecer a", y que el único modo de explicar el significado de dichos conceptos es mediante ejemplos metafóricos. 
con el lugar "hacia donde" se realiza dicho traslado? La pregunta no es superflua, porque de su respuesta dependerá si la metáfora ha de ser considerada como una simple trasposición de palabras o significados, o bien, como el hallazgo de una determinada "semejanza" mediante la facultad que tradicionalmente se llamó el "ingenio"4. Pero la metáfora en general no puede desvincularse de la actividad "ingeniosa", porque ella reposa en último término sobre el hallazgo de significados semejantes entre cosas que se encuentran en planos diferentes.

La metáfora supone, empero, la distinción entre un significado propio y un significado figurado de las palabras. Puesto que nuestro conocimiento empieza con la actividad sensorial, el significado propio de una palabra será el que posee carácter empírico. Sin embargo, observa Grassi, ya el significado "propio" de un término representa una primera forma de metapherein, porque el hecho mismo del lenguaje implica que un determinado sonido carente en sí mismo de significado es transformado en un sonido significante y que, además, como podremos verificarlo más adelante, ostenta un significado perteneciente a un ámbito completamente nuevo y diferente.

Fundándose en los estudios del biólogo Jakob von Uexküll (1864-1944), quien revolucionó la investigación sobre la conducta animal durante la primera mitad del siglo XX, Grassi veía claramente que la realidad sensible es percibida por un ser viviente dentro de ciertos modelos específicos propios de su organismo (Grassi 1970, p. 49 ss.). En la percepción, la realidad adquiere significados diferentes para las diversas especies, porque para todas ellas son diferentes los alimentos, las posibilidades de reproducción y los depredadores. Dichos significados son por consiguiente propios y exclusivos de cada especie y no de los objetos que los exhiben, y en su conjunto constituyen un orden al cual debe adecuarse la conducta de los miembros de la especie, la que de otro modo terminaría por desaparecer. Hay, entonces, ya en un nivel puramente biológico, un metapherein consistente en asignar a las representaciones sensibles significados que son en sí mismos ajenos a los objetos a que éstas corresponden.

Pero no solo en el mundo biológico, sino también en el mundo propiamente humano se produce este metapherein de modelos ordenadores. Ello es evidente en la actividad técnica. El hombre modifica a la naturaleza, utilizando dispositivos que imitan artificialmente a los modelos naturales y que asignan a la naturaleza misma

4 Por lo menos hasta el siglo XVIII se designó como "ingenio" a la facultad humana que permite percibir las semejanzas entre las cosas, en oposición al "juicio”, entendido como la facultad de reconocer sus diferencias. Así, Don Quijote, un hidalgo "ingenioso" que, por mucho leer y poco dormir "vino a perder el juicio", podía, por consiguiente, advertir las semejanzas entre los molinos de viento y los gigantes, o entre las ventas y los castillos, pero no veía las diferencias entre unos y otros. Cfr., por ejemplo: "De los que observan las semejanzas [de las cosas], si son tales que rara vez son observadas por otros, se dice que tienen un buen ingenio (a Good Wit) [...]. Pero de los que observan diferencias y desemejanzas -lo que se llama distinguir, discernir y juzgar entre una cosa y otra- se dice que poseen un buen juicio (a good Judgement) en el caso de que ese discernimiento no sea fácil [...]" (Hobbes, I, 8, p. 43). 
el significado de sirviente puesta al servicio de propósitos humanos. En este nivel, observa Grassi, los traslados de significados (las metáforas) irrumpen por doquier y se establecen también en el lenguaje corriente; y para confirmarlo, cita al gran maestro de la retórica antigua, Quintiliano: "Es por necesidad que los campesinos hablan de las 'yemas' [gemmae, piedras preciosas] o ‘botones' de las vides (¿cómo podrían decirlo de otro modo?), de la 'sed' de los sembrados o del 'sufrimiento' de las cosechas" (Grassi 1970, p. 172)

Más evidente aún es el poder de la metáfora en el ámbito de la creación artística. Como decía Goethe, cuando el artista se apodera de algún objeto de la naturaleza, éste deja de pertenecer a la naturaleza y pasa a depender exclusivamente del artista, que puede transformarlo y, aun, por así decirlo, crearlo de nuevo. Aquí el hombre se muestra ya completamente liberado de los esquemas orgánicos que determinan la conducta de los animales. Si el toro de lidia no tiene otra opción que la de embestir al capote del toreador que ha de darle muerte, el hombre nunca o raramente se encuentra en análoga situación.

Es importante el hecho de que la trasposición metafórica tiene lugar siempre desde el nivel empírico - que constituye el punto de partida de nuestro conocimiento-y, tratándose de expresiones más exclusivamente humanas, hacia un nivel siempre también más alto. Ello se advierte con toda claridad en el término "teoría". Originalmente, la theoría era la designación de los sacrificios, ritos y procesiones que contemplaban los theoroí, esto es, los "contempladores" o embajadores enviados por otras ciudades para que asistieran a las grandes fiestas religiosas en la antigua Grecia. Su significado moderno se origina, por tanto, en una metáfora. Lo mismo vale para la traducción latina de la theoría griega, la contemplatio, que significaba originalmente la acción de los augures romanos al fijar la vista en el templum, es decir, no en lo que hoy llamamos un "templo", sino en el espacio previamente delimitado del cielo en que podía entrar un ave para hacer posible la adivinación del porvenir (Grassi 1970, pp. 173-4).

Grassi sintetiza sus reflexiones hasta este punto con las siguientes palabras: "Resumiendo podemos decir que la metáfora se hace necesaria allí donde se pasa de un ámbito a otro y donde se requiere una nueva determinación; los principios, las archai, no pueden ser esclarecidos con algo distinto, sino solo ser descubiertos y hallados de un modo repentino; el hallarlos es obra de la inventio, del ingenium; su 'in-ducción' desde una solicitación abismal es el origen de todo nuestro conocimiento al reconducir la multiplicidad a las imágenes originarias. La inducción y la metáfora se fundan empero en la visión apremiante de modelos originarios que pueden ser 'vistos' y 'expresados' solo con imágenes. La metáfora se revela desde este punto de vista como la más alta expresión de la experiencia filosófica” (Grassi 1970, p. 174)5.

$* * *$

Aquí y en otros múltiples lugares, utiliza Grassi las expresiones "abismo" y "abismal” con una connotación que es clara en los equivalentes alemanes de estos términos, Abgrund y abgründig, en los que resuena la etimología; Grund significa a la vez fondo y fundamento 
En 1990 se publicó la última obra en que Grassi abordó explícita y sistemáticamente el problema del lenguaje, del lenguaje poético y de la metáfora. El título del libro en italiano (La metafora inaudita) no debe inducir a error. "Inaudita" no significa aquí "aún no escuchada", sino más bien "inaudible", inaudible porque no puede ser pronunciada, debido a que ella se realiza en un nivel en el que por primera vez se forma y adquiere realidad el lenguaje mismo, de modo que ella es fundamento del lenguaje más bien que tropo lingüístico. Hay que tener presente aquí el significado originario del metapherein griego, "traslado, trasposición”. El lenguaje, todo lenguaje, surge ab initio con un traslado y trasposición de significados: ésa es la metáfora inexpresada e inexpresable en el uso comunicativo no analítico del lenguaje, y que es preciso explicar aquí. Por eso, la versión norteamericana de la obra (New York, Binghamton, 1994) traduce adecuadamente el título como The Primordial Metaphor, la metáfora primordial, originaria, esto es, aquella metáfora sin la cual el lenguaje mismo habría sido imposible.

Como es habitual en él, Grassi parte de las concepciones de los pensadores antiguos (Platón, Aristóteles) para ir descubriendo sus fortalezas y debilidades y, de este modo, ir encontrando su propio camino en el análisis y la solución de un problema.

Una lengua, dice pues, está formada por voces (phonai) que consisten a su vez en sonidos (psophoi) dotados de significado. "Voces", en el sentido de las phonai griegas, no significa tan solo nuestras "palabras", sino también las diferentes expresiones del lenguaje animal ${ }^{6}$. En cuanto a su significado, éste no reside en el sonido mismo (el sonido "dulce", por ejemplo, no posee sabor). ¿Estamos, por consiguiente, en la antigua tesis según la cual las palabras reciben su significado por convención (nomos)? No, responde Grassi, porque para lograr un acuerdo cualquiera acerca de una denominación se requiere la existencia previa de una lengua ya formada. El lenguaje es, por consiguiente, natural, no convencional, y los sonidos de los que surge corresponden, en el caso del hombre, a experiencias humanas originarias.

Un sonido es para Aristóteles el efecto mecánico del choque de un cuerpo contra otro, y se trasmite por una vibración del medio (aire, agua). Entre los seres vivientes aparecen en cambio sonidos animados, vinculados con la facultad de la fantasía, que poseen carácter hermenéutico y semántico (voces, phonai). Según Aristóteles, con sus voces pueden los animales expresar el placer y el dolor que experimentan; también los animales vinculan, pues, los sonidos con significados, de donde resulta que el carácter hermenéutico y semántico del lenguaje no es racional ni privativo del logos humano.

o razón, Abgrund es el abismo, cuyo fondo no es visible, y abgründig, abismal, es metafóricamente el fenómeno cuya causa o razón o fundamento no se puede discernir.

6 Los animales, dice Aristóteles, aun cuando no tienen propiamente lenguaje (logos), poseen phoné para expresar su placer y su dolor (Aristóteles, P 1253 a 10 ss.). 
Pero el animal, observa Grassi, dispone de una interpretación innata de los fenómenos, interpretación que comparte con toda su especie. No así el hombre, quien no dispone de tal interpretación innata y se ve obligado a formársela. Por eso es que el lenguaje humano posee carácter histórico, y su historicidad deriva del acierto o del fracaso en los diversos intentos realizados por el hombre para interpretar los fenómenos, atribuyendo significados a los sonidos que los expresan.

El animal obtiene el significado de los fenómenos que percibe gracias a un código específico que le permite "traducir" lo que se le aparece a términos de placer o de dolor. De este modo, la experiencia sensible da lugar en él a una "pasión" determinada que se revela en su conducta. En efecto, toda experiencia sensorial es "padecida" por el viviente, de modo que es, en sentido propio, una pasión. No será necesario recordar aquí que cuando se habla de "pasión" y de "padecer", no se alude únicamente, por ejemplo, a las tremendas pasiones de los personajes de un Shakespeare ni a los padecimientos de horribles dolores y sufrimientos, sino en general a todo cuanto es "pasivo" en la vida cognoscitiva y afectiva. Una pasión es habitualmente relativa a una acción; algunas cosas, las hago -acción-; otras, me las hacen o me ocurren -pasión- sin intervención de mi voluntad; desde esta perspectiva, "padezco" en propiedad todo cuanto me ocurre, lo que "me pasa", y todo lo que de algún modo recibo de fuera, como las impresiones sensoriales, o lo que "me afecta" con independencia de mis voliciones, como el hambre, la sed, la fatiga, no menos que la tristeza o la alegría. Aristóteles señala como característica esencial de las pasiones -y esto será decisivo para la tesis de Grassi- el hecho de ir acompañadas de placer o dolor (Aristóteles $E N$ 1105 b 19 ss.; EE 1220 b 12 ss.; Rh 1378 a 21 ss.). Aquí, de nuevo, no pensemos tan solo en placeres exultantes o dolores atroces e imposibles de soportar, sino también en estados del alma que poseen un carácter aceptable, positivo, y otros caracterizados por su negatividad y la aversión que provocan. Presente está, en todo caso, el carácter de imposición objetiva sobre un sujeto de aquello que él experimentará subjetivamente, padeciéndolo en la experiencia sensorial que constituye el inicio de su conocimiento y de sus posibilidades de comunicarlo.

El código con que el animal reconoce el significado de los fenómenos sensibles no es subjetivo, no es arbitrariamente elegido por el ser viviente, sino que es "padecido" por sus sentidos, que se muestran como meros instrumentos del código correspondiente. Gracias a la función de dicho código se establece una íntima vinculación entre la actividad sensorial, que es el punto de partida de todo conocimiento, y la pasionalidad, origen de toda acción. En este punto, empero, se inserta una crítica y una refutación de Grassi a la teoría aristotélica del lenguaje. Para Aristóteles, la voz (phoné) es un sonido significativo ( $p$ sophos semantikós). Según esto, en el lenguaje estaría implícito un metapherein, una traslación metafórica, porque una señal indicadora (sema) sería trasladada e impuesta a un sonido determinado. Pero, apunta Grassi, la distinción hecha por Aristóteles entre sonido (psophos) y voz (phoné), donde esta última es concebida como sonido indicativo (psophos semantikós), equivale a reconocer la dualidad sujeto / objeto, porque supone un proceso racional en el que un sujeto, enfrentado con un cierto sonido, le introduce una carga semántica y lo deja transformado en voz. Según Aristóteles, un sonido carente en sí mismo de significado "recibiría" una 
señal indicativa que le es impuesta desde fuera. Este dualismo separa el mundo de los sonidos del mundo de los significados. Y si el significado se "traslada" de un mundo al otro, ¿cómo podría asegurarse su objetividad? Porque, ciertamente, cabe siempre la posibilidad de que los significados sean convencionalmente asignados a los sonidos, con lo cual se incurriría en el riesgo de recaer en todos los relativismos sofísticos combatidos por la gran filosofía clásica griega.

En consecuencia, es necesario admitir que el sonido y su significado son inseparables, que constituyen una unidad, dado que el significado "adherido" al sonido no puede derivarse de este último, sino que es conocido únicamente dentro del código del sentido que lo percibe. Tal como lo expresa Grassi, "precisamente porque lo que se manifiesta a través de los sentidos aparece dentro de los límites del placer y del dolor, lo que se manifiesta obtiene siempre, en relación con estos límites, su originario significado pasional indicativo. Debemos inferir, pues, que no existen sonidos, sabores, olores o colores carentes de significado, sino siempre y únicamente 'fenómenos' sensibles significativos. El mundo que se manifiesta a través de los sentidos es nuestro mundo originario; son los sentidos los que abren el telón del teatro, en cuyo escenario aparecemos al mismo tiempo como actores y como espectadores. La voz semántica, indicadora mediante el placer y el dolor, surge de la profundidad de una realidad abismal y originaria, como el indeducible manifestarse instantáneo, sin un antes y un después, sin distinción de causa y efecto, sin un por qué. [....] Pero las consideraciones precedentes ¿logran legitimar la tesis del carácter metafórico del lenguaje en cuanto constituido por sonidos significativos? En tal caso, ¿qué sentido tiene hablar de metáfora? Lo que aparece mediante los sentidos se revela como expresión de un continuo padecer, una solicitación que se identifica y no se identifica, que aparece y que va más allá del ente particular que se manifiesta. Nos hallamos frente a un acontecer originario, al acaecer del mundo del orden, del kosmos sensible" (Grassi 1990 [1], p. 26).

Pero en el caso del hombre, ¿cómo y dónde se revela el código en función del cual aparece el significado de lo real sensible? En las especies animales, el código es innato; para el ser humano no lo es y tiene que ser formado y establecido en cada cual. Para Grassi es claro que la exhibición de códigos posibles es tarea del poeta: “¿No recurre acaso el poeta a la pasionalidad de las voces, de los signos indicativos? ¿No es acaso, desde este punto de vista, un profeta que anuncia en el ámbito del lenguaje lo que ya apremia en los sentidos? Con la pasionalidad de sus palabras, el poeta señala hacia un mundo no racional y misterioso que se abre entre dos oscuridades: la de la physis abismal, racionalmente insondable, y aquella contra la que choca el hombre cuando no halla su orden propio mediante el código sensible y se ve constreñido, por consiguiente, a buscar un nuevo código" (Grassi 1990 [1], p. 30). El poeta no inventa los códigos ni los impone; se limita a mostrar códigos posibles exhibidos a través de personajes o de situaciones particulares. Un ejemplo elocuente de ello es el código del "amor cortés" propuesto por los poetas provenzales del siglo XII y que modeló durante siglos los amores de la juventud occidental; cuando dicho código fue combinado con la figura de la "dama ángel” creada por el boloñés Guido Guinizelli en el siglo XIII, se produjo una seguidilla de poéticos amores, reales o fingidos, pero nunca correspondidos, de poetas amantes de damas que, en su calidad de ángeles, 
morían prematuramente y regresaban al cielo para atraer hacia ellas, desde allá, a sus amantes (así Dante y Beatriz, Petrarca y Laura, Boccaccio y Fiammetta). Con estos códigos recibieron sus significados durante siglos los amores entre hombres y mujeres jóvenes, hasta que nuevos códigos se impusieron y cambió completamente la realidad erótica con sus fenómenos concomitantes.

En suma, todas las impresiones sensibles están cargadas de significados consistentes en indicaciones pasionales que se hacen presentes en el placer o el dolor. Para el pensamiento racional y la ciencia, la experiencia sensible podrá carecer en sí misma de coloración pasional, pero ello significa para Grassi hacer abstracción de un rasgo que es propio, característico y fundamental de la experiencia. "Sólo el mito aterrorizante de la preeminencia de lo técnico y lo mecánico puede afirmar el carácter aséptico de las manifestaciones sensoriales en ese mundo abstracto ofrecido por el pensamiento racional" (Grassi 1990 [1], p. 31). El mundo propiamente humano, concreto, no abstracto, tiene su raíz en esta sensorialidad indisolublemente teñida de pasionalidad. ¿Cómo y por qué adquiere la experiencia sensorial este peculiar carácter en los seres humanos? No hay una respuesta para esta pregunta; ella nos deja, pues, en presencia de un abismo insondable en el que es imposible distinguir el fundamento. Y es precisamente la evocación instantánea de la carga emocional que acompaña a la representación de la imagen sensible, haciendo de ambas un fenómeno simultáneo y una experiencia única, lo que constituye el metapherein originario, la metáfora inaudita e inaudible que imprime su carácter a todo lenguaje. Los sentidos nos ponen en un primer contacto con la realidad entregándonos imágenes visuales, auditivas, etc., que nosotros "apreciamos", esto es, interpretamos no racional sino pasionalmente, porque se presentan dentro de los límites del placer y del dolor; es decir, las "apreciamos" con un "sí" o un "no", positiva o negativamente, según si corresponden o no corresponden a lo que nos apremia dentro de nuestra situación vital. La realidad de los entes en su ser, nos dice Grassi, se manifiesta en el ámbito "de los sentidos, dentro de los límites del placer y el dolor, en las sensaciones originarias que a su vez son la fuente de las pasiones, a saber, en el temor de no ser capaces de identificar el significado de los fenómenos, en la esperanza de lograrlo, en la envidia ante quienes lo hacen mejor, en la benevolencia hacia ellos y el deseo de compartir su esfuerzo para participar en una comunidad de amor y amistad" (Grassi 1990 [1], p. 24). Pero no se trata tan solo de esto. Enfrentamos la nueva realidad que se nos abre mediante la experiencia sensorial con preguntas no expresamente formuladas, pero que, de manera tácita, orientarán nuestra conducta ante ella: la situación que la experiencia revela ¿satisface mis actuales necesidades o constituye más bien un impedimento para satisfacerlas? ¿La abrazo placenteramente o la rechazo y procuro evitarla, porque afecta negativamente mi proyecto vital? Esta correspondencia o no correspondencia entre lo que los sentidos nos anuncian y las solicitaciones y apremios del momento que vivimos abre la posibilidad de una profunda y a la vez misteriosa "objetividad sensorial", que Grassi había estudiado ya en una obra anterior, en la que contraponía la objetividad propia de las 
percepciones sensibles a la objetividad abstracta de los instrumentos construidos para medir los fenómenos dentro de parámetros racionales (Grassi 1974) 7 .

¿Pero no está introduciendo inadvertidamente Grassi un nuevo dualismo al proponer la tesis de la pasionalidad de la experiencia sensible? ¿No sería éste el dualismo de la pasión subjetiva propia de la vida sensorial -pues el viviente dotado de sentidos "padece" las señales indicadoras que en forma de placer o dolor recibe en la experiencia sensorial-y de un mundo objetivo ajeno a la vida de los sentidos y que de suyo no envía ni posee la función de enviar señales patéticas a seres eventualmente cognoscentes? En otras palabras, ¿no estamos frente al dualismo de las "cosas en sí", incognoscibles por ser carentes de significados, y de las "cosas para nosotros", dotadas de significados manifiestos a través de la pasionalidad?

Recordemos en este punto el principio heideggeriano fundamental de la diferencia ontológica, que Grassi mantiene siempre presente a lo largo de su investigación. Este principio no establece un dualismo entre ente y ser, porque si bien ambos no son lo mismo y no han de confundirse, resultan a pesar de ello inseparables, no es posible concebir al uno sin el otro y solo pueden distinguirse mediante un proceso de abstracción. Análogamente, el carácter pasional de la experiencia sensible es inseparable de la experiencia misma, aun si es distinto de su carácter estrictamente representacional. Si en la experiencia sensible se dan simultáneamente la representación del objeto y su significado, no puede haber dualismo sino que, por el contrario, la mera representación despojada de su significado sería una abstracción, así como también lo sería el solo significado concebido en forma aislada, sin la representación de un ente que lo posea y lo exhiba. El ente "sonido" podrá exhibir uno de sus aspectos, como lo advirtió Aristóteles, en la forma de una vibración del medio producida por el choque entre diversos cuerpos, y como tal podrá ser manipulado y alterado por expedientes físicos, pero el ser amable o bello o inquietante o amenazador de un sonido no depende ciertamente de las manipulaciones físicas que puedan alterarlo. En efecto, un mismo fenómeno, por ejemplo la audición de los Rückert-Lieder de Mahler, puede tener muy distintos significados objetivos para diferentes personas que compartan la experiencia, como por ejemplo, un musicólogo, un compositor de música, un director de orquesta, un maestro de canto, un poeta, un editor o un comerciante de discos fonográficos, para no mencionar a quienes solo gustan (subjetivamente, por cierto) de los valses y polcas de Johann Strauss hijo y de Emil Waldteufel.

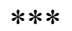

En esta obra muestra Grassi el contraste, por ejemplo, entre la objetividad concreta de la percepción de distancia a través de los sentidos del tacto y del olfato, y la objetividad abstracta de la misma percepción a través de la lectura de un cuentakilómetros o de un reloj. 
Hemos considerado hasta aquí la interpretación de la metáfora realizada por Grassi en dos períodos diferentes separados por un espacio de veinte años, uno que culmina con la publicación de Macht des Bildes en 1970, y el otro, coronado por $L a$ metafora inaudita de 1990. Por razones obvias, hemos enfatizado más bien las diferencias y no las semejanzas entre ambas obras. Ello podría dar lugar a creer que durante ese tiempo se produjo un cambio en la concepción y el tratamiento del tema de la metáfora y del lenguaje poético en Grassi. Ello, sin embargo, no es así. La idea central que anima la reflexión de 1990 -a saber, la del metapherein originario que tiene lugar entre el ámbito de lo representacional y el de lo pasional en toda experiencia sensible humana y, por consiguiente, también en todo lenguaje-, estaba ya en germen, si bien aún no desarrollada, en la obra de 1970, como puede comprobarse en el siguiente pasaje de ella:

“¿Cómo puede distinguirse el 'sentido propio' [Eigentlichkeit] de una palabra de su sentido traslaticio? La existencia humana se inicia reconduciendo (anagogé) las apariencias sensibles a modelos originarios [Typen]. El sentido propio primario de una palabra consiste, pues, en su significado empírico. Éste, por su parte, representa una primera forma del metapherein, porque, digamos, en el instante mismo en que a un rumor se le asigna un significado, él se transforma en un sonido significativo. Así hablamos, por ejemplo, de un 'sonido horroroso' o, en otros ámbitos sensoriales, de un sabor 'fuerte', de un color 'seductor' o 'espantoso', o de un movimiento 'imperioso'. Puesto que la metáfora comparece aun en las más simples constataciones empíricas, debemos reconocer que ella participa por principio en la construcción de nuestro mundo" (Grassi 1970, p. 170).

Es claro que en este texto subyace la idea de la metáfora "inaudita" o "primordial", junto con la noción de que dicho metapherein se orienta siempre hacia el ámbito de lo pasional; en él falta únicamente precisar, como lo hizo Grassi más tarde, que dicha transferencia no es un "proceso" que tiene lugar en el tiempo, sino que se realiza instantáneamente en el acto mismo de hacer la experiencia sensible. Obviamente, los análisis y observaciones que conducen a estos resultados son y tienen que ser siempre muy semejantes, si no los mismos. Este hecho dice relación con lo que cualquier lector de Grassi puede observar aun en una lectura superficial de sus obras, que es la frecuente repetición de argumentos y textos de apoyo para sustentar sus tesis. Aparte de que ello se explica en parte porque él publicaba para públicos de diferentes nacionalidades en diversas lenguas (alemán, italiano, francés, castellano, inglés y aun serbocroata), es claro también que, si se repite, lo hacía por tener ante la mirada del espíritu un mismo problema fundamental que debía ser considerado desde diferentes puntos de vista y distintas perspectivas, de manera tal que éste reaparecía una y otra vez en las más diversas circunstancias y contextos. La insistencia en un mismo problema y sus ramificaciones puede parecer extemporánea en nuestra época, en que la lluvia de informaciones y datos de toda índole inunda todos los ámbitos del saber, y en que domina abiertamente la especialización o, en su defecto, la superficialidad. Pero es valioso reiterar la aspiración a la unidad del saber ya expresada por el viejo 
Heráclito: "Lo sabio es únicamente compenetrarse del pensamiento de que todo es gobernado por todo" (Frg. B 41, Diels) ${ }^{8}$.

¿Qué consecuencias, podemos preguntarnos, se siguen entre otras de las tesis planteadas hasta aquí por Grassi?

En primer lugar, el problema del metapherein en el lenguaje se escapa de la esfera de la estética y de la teoría literaria, para instalarse en el corazón mismo de la investigación filosófica del ser y del lenguaje. Si, como quería Heidegger, solo donde hay lenguaje surge el problema del ser, y si, según Grassi, el lenguaje nace en una traslación del significado de los contenidos de la experiencia sensible desde un ámbito puramente representacional hacia un ámbito pasional, entonces el problema del metapherein ya no es un problema literario y se constituye en problema metafísico, ontológico. Con ello, la metáfora deja de ser únicamente asunto de los poetas, o bien, si se prefiere, el hombre, en cuanto hablante, "habita poéticamente", como lo dice Hölderlin. Y ya que la metáfora deberá necesariamente continuar siendo estudiada como una figura literaria en el sentido tradicional, acaso sería mejor no designar la traslación de ámbito identificada por Grassi como una metaphorá, que sugiere un traslado deliberado y voluntario, sino como una metabolé que tiene lugar sin intervención consciente de quien padece la experiencia.

En segundo lugar, el camino recorrido por Grassi para identificar la metáfora originaria en la raíz del lenguaje a través de la experiencia sensible, estaba previamente insinuado, si bien no manifiesto, en la noción de la diferencia ontológica. Porque si el ser sobrepasa y excede a los entes que le sirven de "portadores" y que de un modo $\mathrm{u}$ otro lo manifiestan, el ser constituye precisamente aquello abismal no formulable en enunciados lógicos, que subyace a nuestras experiencias originarias y les confiere sentido. La postura heideggeriana consiste en la búsqueda del sentido del ser, que no es accesible a través de la investigación de los entes en cuanto objetos del conocimiento porque ésta supone el dualismo sujeto / objeto propio de la tradición racionalista y de la metafísica onto-teo-lógica. Si, por consiguiente, para el Dasein se da algo así como el "ser", éste tiene que ser accesible a través de la experiencia de los sentidos si no queremos volver a afirmar la realidad trascendente de las ideas platónicas. Para Grassi, es precisamente el metapherein originario que acompaña a la experiencia sensible lo que delata al ser que se manifiesta en los entes sin identificarse con ellos. Explicando un texto del humanista Coluccio Salutati, comenta Grassi: “QQué es hablar

8 Acaso sea pertinente mencionar aquí mi experiencia personal cuando, en el inicio de mis estudios de filosofía, tuve la oportunidad de asistir a algunos seminarios de Grassi; de quien nada sabía y nada había leído; mi primera impresión intuitiva acerca de él fue la siguiente: "este hombre sabe una sola cosa, ignoro cuál, pero esa sola cosa le permite arrojar luz sobre todas las restantes". 
metafóricamente? Es la transferencia del significado de los entes a un nuevo nivel, a saber, al nivel de los seres humanos. Mediante la metáfora, el ser se clarifica y se manifiesta en su significado para el hombre. En consecuencia, por el lenguaje metafórico el ser se revela en general entrando en la apertura del mundo humano. La ciencia tiene su raíz en el pensar y el hablar metafóricos, es decir, en la palabra poética" (Grassi 1990 [2], p. 153).

En tercer lugar, si la revelación del ser de los entes se da en los límites del placer y del dolor, esto es, en una dimensión pasional afectiva, entonces la "lógica" de la afectividad y de la pasionalidad, aún no suficientemente estudiada, debe anteceder a la lógica de la razón, que la tradición occidental ha escudriñado y formalizado de manera admirable 9 . Con ello, se legitima y se impone de manera inmediata la importancia de la identificación hecha por Grassi de una tradición occidental de humanismo retórico, por cuanto la retórica es la disciplina que estudia las pasiones y los modos de estimularlas y de dominarlas, así como la dialéctica es la disciplina que hace lo propio con la razón y sus mecanismos intelectuales. Es, por tanto, una tradición que para Grassi, a despecho de Heidegger, no padeció de ceguera ni de amnesia respecto del auténtico problema del ser.

\section{Referencias bibliográficas}

Aquino, Sto. Tomás de (1950), (ST), Summa theologiae, cura et studio Sac. Petri Caramello. Taurini-Romae: Marietti.

Aristóteles (1947), (EN), The Nicomachean Ethics, with an English translation by $H$. Rackham. M. A., Cambridge, Mass.: Harvard University Press.

(1950), (P) Politics, with an English translation by H. Rackham. M. A., Cambridge, Mass.: Harvard University Press.

(1952), (EE) The Athenian Constiutution. The Eudemian Ethics. On virtues and vices, with an English translation by H. Rackham. M. A., Cambridge, Mass.: Harvard University Press.

(1953), (M) Aristotle's Metaphysics. A revised text with Introduction and Commentary by W. D. Ross. Oxford: The Clarendon Press. 2 vols.

(1957), (Rh) Aristotle. The "Art” of Rhetoric, by John Henry Freese. Cambridge, Mass.: Harvard University Press.

Descartes, René (1976), Discours de la méthode, Texte et commentaire par Étienne Gilson, Paris: Vrin, $5^{\mathrm{a}}$ ed.

Diels, Hermann (1951), Die Fragmente der Vorsokratiker. Sechste verbesserte auflage hg. von Walther Kranz. Berlin-Grünewald: Weidmann. 3 vols.

9 Grassi bosquejaba ya una "lógica" de la metáfora y de la "visión de semejanzas" sobre la que reposa, en Grassi 1980 pp. 94-101. 
Grassi, Ernesto, (1933), Dell'apparire e dell'essere, Firenze: La Nuova Italia.

(1946), Verteidigung des individuellen Lebens. Studia humanitatis als philosophische Überlieferung, Bern: Francke.

(1951), "Das Problem der Objektivität"; "Von den Stufen des Objektiven", Die Einheit unseres Wirklichkeitbildes und die Grenzen der Einzelwissenschaften (E. Grassi, T. v. Uexküll, eds.). München: Leo Lehnen Verlag.

(1957), Kunst und Mythos, Hamburg: Rowohlt. Traducción castellana: Arte y Mito, Buenos Aires: Nueva Visión (1957).

(1970), Macht des Bildes: Ohnmacht der rationalen Sprache. Zur Rettung des Rhetorischen. Köln: DuMont Schauberg.

(1974), Reisen ohne anzukommen. Eine Komfrontation mit Südamerika. München-Gütersloh-Wien: Bertelsmann. Traducción castellana: Viajar sin llegar. Un encuentro filosófico con Iberoamérica. Barcelona: Anthropos (2008).

(1979), Die Macht der Phantasie. Zur Geschichte abendländischen Denkens. Königstein/Ts.: Athenäum. Traducción castellana: El poder de la fantasia.Observaciones sobre la historia del pensamiento occidental. Barcelona: Anthropos (2003).

(1980), Rhetoric as Philosophy. The Humanist Tradition. University Park and London: The Pennsylvania State University Press.

(1983), Heidegger and the Question of Renaissance Humanism, Four Studies. Binghamton/N.Y.: State University of New York at Binghamton. Traducción castellana: Heidegger y el problema del humanismo. Barcelona: Anthropos (2006).

(1986), Einführung in philosophische Probleme des Humanismus. Darmstadt: Wissenschaftliche Buchgesellschaft. Traducción castellana: La filosofia del Humanismo. Preeminencia de la palabra. Barcelona: Anthropos (1993).

(1987), La preminenza della parola metaforica. Heidegger, Meister Eckhart, Novalis. Modena: Mucchi.

(1990 [1]), La metafora inaudita. Palermo: Aesthetica.

(1990 [2]), Vico and Humanism. Essays on Vico, Heidegger, and Rhetoric. New York: Peter Lang. Traducción castellana: Vico y el humanismo. Ensayos sobre Vico, Heidegger y la retórica. Barcelona: Anthropos, (1999).

Heidegger, Martin (1951), Erläuterungen zu Hölderlins Dichtung. Frankfurt am Main: Klostermann, $2^{\mathrm{a}}$ ed.

(1958), Der Satz vom Grund. Pfullingen: Neske, $2^{\mathrm{a}}$ ed.

(1984), Hölderlins Hymne Der Ister, (GA, Bd. 53). Frankfurt am Main: Klostermann.

Hobbes, Thomas (1960), Leviathan, or the matter, forme and power of a Commonwealth ecclesiastical or civil, M. Oakeshott, ed. Oxford: Blackwell.15. 